One approach to selecting those at high risk of disability is to identify the very old ( 85 or older), those recently discharged from hospital, the recently bereaved, and those taking multiple medications. Taylor claimed that only the first two of these categories were likely to be valid indicators of high vulnerability. ${ }^{5}$ Another approach has been using postal questionnaires, ${ }^{67}$ and a recent initiative has used volunteers to visit all older people; those identified to be in need are then followed up by general practitioners, health visitors, and district nurses. ${ }^{4}$

Freer has shown the feasibility of opportunistic case finding, which takes advantage of the fact that three quarters of old people contact their general practitioners at least once a year. This contact may be used to ask questions and make observations aimed at identifying those at high risk, who may then be offered further assessment. ${ }^{8}$ Several studies have shown the benefits of planned programmes of case finding that concentrate on functional assessment. ${ }^{.10}$ The time has come to implement the programmes in primary care to improve the quality of life for vulnerable old people and reduce the need for continuing institutional care.

It would be unfortunate, however, if the recent government interest in prevention for older people was to be channelled into medical screening. We suggest rather that case finding should be encouraged (by financial inducements and otherwise). Evaluation should be an integral part of the case finding programmes and should consider "life satisfaction," which case finding seems to improve."

E G BUCKLEY

General Practitioner,

Howden Health Centre,

Livingstone, West Lothian EH54 6PT

Professor Emeritus,

J WiLliamson

University of Edinburgh,

Edinburgh EH4 1PJ

\footnotetext{
1 Secretaries of State for Social Services, Wales, Northern Ireland, and Scotland. Promoting better health. The government's programme for improving primary health care. London: HMSO, 1987. 2 The South-East London Screening Study Group. A controlled trial of multiphasic screening in middle age. Int f Epidemiol 1977;6:357-63.

Olsen DM, Kane RL, Protor PH. Controlled trial of multiphasic screening. $N$ Engl f Med 1976;294:925-30.

Taylor RC, Buckley EG, eds. Preventive care of the elderly: a review of current developments. Occasional paper 35. London: Royal College of General Practitioners, 1987.

5 Taylor RC, Ford GG. The elderly at risk. A critical examination of commonly identified risk groups. f R Coll Gen Pract 1983;33:699-700.

6 Barber JH, Wallis JB, McKeating E. A postal screening questionnaire in preventive geriatric care. IR Coll Gen Pract 1980;30:49-51.

7 Duke OARS. Multidimensional functional assessment. Durham, NC: Duke University Medical Care, 1978.

8 Freer CB. Consultation-based screening of the elderly in general practice: a pilot study. $f R$ Coll Gen Pract 1987;37:455-6.

9 Vetter NJ, Jones DA, Victor CR. Effect of health visitors working with elderly patients in genera practice. BrMed f 1984;288:369-72.

10 Hendricksen C, Lund E, Stromgard F. Consequences of assessment and intervention among elderly people: a three year randomised controlled trial. Br Med f 1984;289:1522-4.

11 Tulloch AJ, Moore V. A randomised controlled trial of geriatric screening and surveillance in general practice. $\mathcal{F} R$ Coll Gen Pract 1979;29:733-42.
}

\title{
DNA topoisomerases in cancer treatment
}

DNA topoisomerases have emerged in the past three years into the clinical limelight. ${ }^{1}$ They were first identified over 15 years ago as important enzymes in bacterial systems, but recent work has shown that they may be unique targets for anticancer drugs.

There are two enzymes-topoisomerase 1 and topoisomerase 2. Their name arises from their crucial function in catalysing the conversion between topological isomers of DNA. They assist in relaxing and supercoiling DNA, intertwining DNA into rings, and tying knots and untying them again, and they may act as swivels to reduce the torsional stress when DNA is transcribed by RNA polymerase. DNA topoisomerases stop the double helix of DNA tying itself into an impossible tangle when it has to divide into two single strands. They can create a break in either one strand (topoisomerase 1) or in both strands (topoisomerase 2 ), allowing one strand or both strands to pass through the gap. They then catalyse the resealing of the gateway.

Topoisomerase 1 seems not to be essential for bacteria or cells, whereas topoisomerase 2 is. Most attention has therefore been paid to possible drug interactions with topoisomerase 2, and it has become clear that it is the target for several DNA intercalating agents, such as doxorubicin, elliptocines, amsacrine, and the epipodophyllotoxinsteniposide and etoposide. Teniposide binds to topoisomerase 2 , thus stabilising the cleavage complex formed between topoisomerase 2 and DNA strands. This complex is associated with cell death. The precise reason for cell death is not known, but several elegant experiments have suggested that the cytotoxicity of the drugs is related to the production of double strand breaks (but not single strand breaks). Topoisomerases seem to mediate drug induced cytotoxicity independently of free radical production.

The selectivity of cytotoxic drugs acting through topoisomerase may be partly explained by the enzyme being present in low concentrations in resting cells and increasing in concentration in tissues proliferating in response to growth factors. The concentration increases in human leukaemic cells when they enter the cell cycle and is high in solid tumours such as adenocarcinoma of the prostate. A further interesting finding is that erythroleukaemia cells in the mouse have a high concentration of topoisomerase, which falls dramatically after differentiation is induced by adding hexamethylene bisacetamide. It may also be important that topoisomerase 2 sequences have been reported in certain genes, including the proto-oncogene $\mathrm{c}-\mathrm{fos}$, and that etoposide and amsacrine both stimulate breaks in exon 1 of the c-myc proto-oncogene. It may be therefore that some activated oncogenes are the targets for drugs that work through topoisomerase 2 .

Resistance of tumour cells to cytotoxic drugs has obvious clinical interest, and tumour cell lines in tissue culture have shown two sorts of resistance to inhibitors of topoisomerase 2: cell lines from patients with chronic lymphatic leukaemia that are resistant to adriamycin have low concentrations of human topoisomerase 2 , while Chinese hamster cells resistant to etoposide show a mutant form of the enzyme. Other factors may be important in resistance-for instance, drug uptake and alterations of the catabolism of the topoisomerase cleavable complex. A prospective study is now underway in patients with myeloid leukaemia to try to predict the likelihood of response to amsacrine by screening for low topoisomerase concentrations, mutant enzymes, or both.

The clinical importance of unravelling this novel mechanism of action may be limited, but predictive testing is an exciting and logical consequence of the basic work. Furthermore, the interaction between epipodophyllotoxins and topoisomerase 2 explains the importance of giving teniposide and etoposide at the right time and in the right relation. This new information may also give us more clues about the 
optimal combinations of other drugs_-for example, cell lines resistant to nitrogen mustard have an increased concentration of topoisomerase 2 , which suggests that they might be better treated by etoposide or teniposide and that the combination of mustard and etoposide would be logical in attempting to prevent resistance emerging. Combinations of specific growth factors which switch tumour cells to cell division followed by a drug targeted at topoisomerase 2 would be interesting, and there are already data from in vitro studies to show that antimetabolites and tumour necrosis factor enhance the cytotoxicity of drugs that act on topoisomerase 2. Another logical development would be to develop a mutant of topoisomerase 2 . And, finally, topoisomerase 1 should not be forgotten because in several cell types it seems to be part of the mechanism by which the cytotoxic drug camptothecin kills cells.

Director of Clinical Research,

Netherlands Cancer Institute,

1066 CX Amsterdam,

The Netherlands

1 Potmesil M, Ross WE, eds. Topoisomerases in cancer treatment. Bethesda: National Cancer Institute, 1987. (NCI Monographs No 4.)

\section{Spring changes to the social security system}

During 1987-8 the government estimated that at any one time over five million people were receiving supplementary benefit. This benefit acted as a safety net in the social security system by providing a basic income for those with no other source of income or an income too low to maintain themselves and their dependants. During the same period another three and half million people were receiving help with rent and rates through housing benefit and over 200000 families in low paid work were receiving family income supplement. Nearly nine million people (plus their dependants) were thus relying to some extent on means tested benefits. Of these nearly a million were sick or had disabilities and four and half million were elderly - many of whom would also have had health or disability problems.

These means tested benefits have now been fundamentally altered by the full implementation of the Social Security Act 1986. Supplementary benefit has been replaced by income support, family income supplement by family credit, and single payments for one off needs by the social fund; the housing benefit scheme, while retaining the same name, has also been completely revised to bring it into alignment with income support. The government's aim in making these changes has been to provide a simpler system of benefits that will target resources more effectively at those in greatest need. It has also wanted to remove the anomaly whereby people in work might be worse off than those claiming benefit. To achieve these aims the government has produced a less complicated system with tighter rules. Unfortunately, this will mean rough justice for some, and as the new scheme is being introduced within a limited budget many claimants have found that they are getting less under the new system than they were under the old.

The simplification of supplementary benefit has been achieved by replacing a system that tailored benefit to individual needs with one that defines needs in terms of broad based "client" groups. Under the old system people were given a basic allowance for everyday needs and could claim for needs such as special diets, extra heating, or extra shoes or clothing (if, for instance, they wore out quickly because of a disability). The new scheme provides a basic personal allowance that may then have added to it a weekly "premium" depending on family responsibilities and needs arising out of old age, sickness, or disability. The premium is at a flat rate and therefore does not necessarily reflect the actual extra costs that a particular person may have to meet. In general, the more frail an elderly person or the greater the degree of disability the less adequate the premium is likely to be. Additionally, some people who have needs arising out of disability or health problems are not entitled to a premiumfor example, diabetics cannot claim for special diets.

There are three premiums relating to disability, and the circumstances in which they will be awarded are tightly defined.

The disabled child premium will be paid if there is a child in the family who is either registered blind or receiving an attendance or mobility allowance.

- The disability premium will be paid if the claimant or partner is receiving an attendance allowance, mobility allowance, invalidity allowance, or severe disablement allowance. It will also be paid if the claimant (but not the partner) has been unable to work because of ill health for 28 weeks.

- The severe disability premium will be paid only if the claimant is receiving an attendance allowance, no one is receiving invalid care allowance for looking after him or her, and he or she meets a DHSS definition of "living alone."

This same system of basic allowance plus premiums will be used in calculating housing benefit for people (many of them elderly) who are not entitled to income support.

Thus the inability of the new scheme to respond flexibly to individual needs means that showing entitlement to a premium will be crucially important in determining a claimant's benefit. Those such as doctors who come into regular contact with sick and disabled people may be able to identify those who could claim one of the qualifying benefits (such as an attendance or mobility allowance) for these premiums. In addition to identifying potential claimants, doctors can also improve the chances of claims succeeding by giving detailed and relevant supporting evidence to patients making claims.

Doctors may also be affected by the replacing of single payments for one off needs (such as a bed or cooker) with discretionary payments from a cash limited social fund. Guidance has been given to social fund officers to help them decide how to allocate the limited money available. They will have to identify groups that may have greater needs-for example, people with disabilities, elderly people, and people who are chronically sick. Doctors may be approached by patients for medical evidence to support applications for a social fund payment. A full report from a claimant's general practitioner could strengthen such an application.

These are only a few of the benefit changes which will affect patients' lives. There will be other times when doctors will be called on to support patients trying to obtain help, and doctors need to understand how crucial this support may be.

ANNE KETLEY
JANICE TURNER

Information Officers,

National Association of Citizens Advice Bureaux, London N1 9LZ 